\title{
Small Wind Turbines in Turbulent (urban) Environments: A Consideration of Normal and Weibull Distributions for Power Prediction
}

\author{
Keith Sunderland \\ Technological University Dublin, keith.sunderland@tudublin.ie \\ Thomas Woolmington \\ Technological University Dublin, thomas.woolmington@tudublin.ie \\ Jonathan Blackledge \\ Technological University Dublin, jonathan.blackledge@tudublin.ie
}

See next page for additional authors

Follow this and additional works at: https://arrow.tudublin.ie/engscheleart2

Part of the Power and Energy Commons

\section{Recommended Citation}

Sunderland, K., Woolmington, T., Conlon, M., Blackledge, J. : (2013) Small wind turbines in turbulent (urban) environments: A consideration of normal and Weibull distributions for power prediction, Journal of Wind Engineering and Industrial Aerodynamics. Vol.121 , p70-81 doi:10.1016/j.jweia.2013.8.001

This Article is brought to you for free and open access by the School of Electrical and Electronic Engineering at ARROW@TU Dublin. It has been accepted for inclusion in Articles by an authorized administrator of ARROW@TU Dublin. For more information, please contact arrow.admin@tudublin.ie, aisling.coyne@tudublin.ie, gerard.connolly@tudublin.ie.

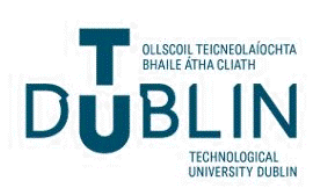




\section{Authors}

Keith Sunderland, Thomas Woolmington, Jonathan Blackledge, and Michael Conlon

This article is available at ARROW@TU Dublin: https://arrow.tudublin.ie/engscheleart2/70 


\title{
SMALL WIND TURBINES IN TURBULENT (URBAN) ENVIRONMENTS: A CONSIDERATION OF NORMAL AND WEIBULL DISTRIBUTIONS FOR POWER PREDICTION
}

\begin{abstract}
The urban terrain and the associated morphological complexities therein, present significant challenges for the deployment of small wind turbines. In particular, a considerable amount of uncertainty is attributable to the lack of understanding concerning how turbulence within urban environments affects turbine productivity. Current wind turbine power output measurements (particularly for small/micro wind turbines) are based on an average wind speed over an observation period; with limited accountability of the variability of wind speed within the observation time frame. This paper however, presents two models that can instead accurately consider such wind speed variation and how it affects the turbine, based solely on the observed mean wind speed and standard deviation within successive (10 minutes) time intervals. These models are predicated on an appreciation of the industry standard metric, turbulence intensity (TI), in conjunction with the power curve of a $2.5 \mathrm{~kW}$ wind turbine. Simple 'look-up' tables collating how the turbine's power curve is affected by varying TI are used so that a novel methodology for estimating the turbine's electrical performance, is achievable Ultimately, the two models presented afford an opportunity to provide an indicative real-world wind speed distribution based on the two standard measurements. The first approach is an adaptation of a model originally derived to quantify the degradation of power performance of wind farm turbines, using a Gaussian probability distribution to simulate turbulence (and more specifically, turbulence intensity (TI)). Such Gaussian modelling has potential however, for disproportionately high and asymptotic TI, associated, for example, with gusting within low mean wind speed observation windows. Furthermore, the approach requires an accurate turbine power curve. The second approach overcomes these limitations through the novel application of the Weibull Distribution, a widely accepted means to probabilistically describe wind speed. Both models are tested at an urban and suburban location in Dublin City, Ireland, where sonic anemometry is positioned at approximately 1.5 times the average height of buildings at the respective locations. Both observation sites represent two distinct urban landscapes. The instrumentation is positioned specific to their surrounding locations and, record the three dimensional wind vectors at a temporal resolution of $10 \mathrm{~Hz}$. The hypotheses presented here consider an idealised electrical performance of the turbine, with results suggesting that both approaches can replicate very accurately this idealised basis.
\end{abstract}

\section{Highlights}

- The performance of wind turbines in an urban environment is considered using Guassian statistics and the application of the Weibull distribution

- Turbulence is quantified and analysed in terms of the turbulence intensity (TI) metric; as observed at two sites in Dublin City

- Two models that employ a novel approach to achieve a very high resolution evaluation of turbine output power

- The models only require the mean wind speed and standard deviation over observation windows of 10 minutes to evaluate turbine power

\section{Keywords}

Small wind turbines, urban environments, turbulence, turbulence intensity, Gaussian and Weibull distributions

\author{
Authors:

\section{Corresponding Author} \\ Keith Sunderland, \\ School of Electrical Engineering Systems \\ Dublin Institute of Technology, \\ Kevin St., Dublin 8 \\ Ireland \\ e: keith.sunderland@dit.ie \\ ph.: +353-1-4024882
}

Keith Sunderland, Dublin Institute of Technology (keith.sunderland@ dit.ie)

Thomas Woolmington, Dublin Institute of Technology (thomas.woolmington@ dit.ie)

Jonathan Blackledge, Dublin Institute of Technology (jonathan.blackledge59@ gmail.com)

Michael Conlon, Dublin Institute of Technology (michael.conlon@ dit.ie) 


\section{Introduction}

Wind turbines extract kinetic energy from moving air, converting it into mechanical energy via the turbine rotor and then into electrical energy through the generator:

$$
P=\frac{c_{p} \cdot \rho \cdot A \cdot u^{3}}{2}
$$

where the mechanical output power $(P)$ is a function of the performance coefficient of the turbine $\mathrm{c}_{\mathrm{p}}$, the density of air $(\rho)$, the area swept by the turbine projected in the direction of the wind $(A)$ and wind-speed $(u)$. In the conversion of mechanical energy into usable electricity, aerodynamic conversion losses are high. According to the Betz limit, the maximum possible conversion coefficient of a wind rotor is $59.3 \%$. However, in practice losses due to (aerofoil) blade roughness, wake effects, hub loss and tip losses reduce the efficiency considerably. If the wind is unsteady the energy conversion capability of the turbine is further degraded.

There are many challenges to incorporating wind generation into urban areas. In considering where these technologies are likely to be installed, little is known of the wind resource in these environments and due to the very rough and heterogeneous landscapes, turbines close to the urban surface will experience site-specific, localised turbulence. Some researchers have employed computational fluid dynamic modelling to ascertain the potential of building mounted turbines [1-3]. These works demonstrates the significance of turbine position and mounting height vis-a-vis the building, such that small changes in location can have dramatic effects on the power generated. Such analyses is very (computationally) resource intensive and validation of results is very difficult to achieve. A number of studies have indicated that turbines installed in urban environments are subject to turbulence. These installations appear to underperform when compared to installations in non-turbulent environments. For example, both the Warwick Field trials [4] and the Energy Savings Trust monitoring programme [5], concluded that problems such as the development of localised turbulence could reduce generation output considerably. The Energy Savings Trust monitoring programme found that turbine outputs in urban locations corresponded to a load factor of less than 3\%. Vertical Axis Wind Turbines (VAWT) have been shown to be less affected by turbulent wind streams and it is deduced that this is due to the fact that there is no yawing mechanism associated with these turbines (i.e. turbines do not have to turn to face the wind). However they are still subjected to pulsating wind speeds due to eddies/gusts etc.

In contrast, there is significant research assessing the wind energy resource in 'rural' locations around the world [6-10], and in some research [9, 10], this work has been extended to apply to the potential for wind energy conversion systems. Notwithstanding the issues in urban environments however, if a renewable solution to increasing energy demand is to be achieved, wind energy - especially where civil populations are increasingly concentrated - must be explored.

The objective of this paper is to establish a simple means by which the effect on electrical power output of a wind turbine in a turbulent environment can be established. While wind turbine productivity is also affected by 
mechanical constraints such as how quickly the turbine can react to changing wind directions, for the purpose of this paper, the electrical considerations are prioritised. Two mathematical models are proposed that respectively utilise Gaussian statistics and the Weibull distribution to accurately model the consequences on turbine productivity within turbulent environments. These models are facilitated through look-up table(s) that describe the turbulence affected turbine electrical power in terms of wind speed and calculated TI. In this way, turbine output on the basis of mean wind speed and standard deviation over an observation period (10 minutes) is possible; both of which are standard parameters within the measurement spectrum of practical wind turbines. These models are tested at two locations within Dublin City, Ireland that are characterised as sub-urban and urban At both locations, high resolution (sonic) anemometry samples the wind resource at $10 \mathrm{~Hz}$ at a height of about 1.5 times the average building height. As these sites are selected as being representative of a specific urban landscape, the paper uses the analysis as a basis for discussion considering how surface roughness might be linked to the models developed.

\section{The Urban Wind Resource and Energy Harnessing in a Turbulent Context}

Urban wind regimes are characterised as having low wind speeds with more turbulent flow that results in limited energy realisation. Air flowing across an urban area will interact with the underlying urban subtype and become affected by its characteristics. The dominant process in the lower atmosphere is convection. The type of convective activity, as described in Oke's work on boundary layer climatology, is influenced by the vertical temperature structure as expressed by stability [11]. There are three classifications used: unstable, stable and neutral. As a consequence of heat output from the city, urban climates tend to be more unstable than neutral [12]. However, as discussed in [13] for the sites considered in this research, it was ascertained that at Dublin Airport (circa 10km from Dublin city centre), 86\% of data for the period November 2010 to December 2011 were classified as $D$, according to the Pasquill-Gifford stability index. When one also considers the propensity for strong winds across Dublin city, one can assume a neutral atmosphere at both sites considered here, where the majority of turbulent air flow is manifested mechanically. This position is consistent with the research carried out by Metzger and McKeon [14] where they demonstrate that in neutral environments, surface roughness dominates turbulence production. The authors further suggest that in the consideration of wind flow and turbulence, the wind resource is dependent on the mechanical effects of surface roughness.

Within rural environments, the $\log$ wind profile (2) is commonly employed as a means of estimating the wind resource.

$$
u(z)=\frac{u_{*}}{\kappa} \cdot \ln \left(\frac{z-z_{d}}{z_{0}}\right)
$$

where, $z_{0}$ is the roughness length and $z_{d}$ is the displacement height; the roughness length is a measure of the drag exerted on the wind by the underlying surface - higher values indicating more drag. The displacement height $\left(z_{d}\right)$ is the effective zero wind speed height. In this way, this "effective ground level" is not the base of the buildings but some point within the vertical plane of the urban canopy and represents the level at which the 
$\log$ relationship might produce zero wind, whereas, varying $z_{d}$ changes the effective origin from which height is measured. The frictional velocity $\left(u_{*}\right)$ is a measure of the shearing stress that drives the flux of momentum to the Earth's surface. This relationship (illustrated in Figure 1) describes wind-speed in the direction of airflow within a boundary layer where airflow has adjusted to the underlying surface. It is properly applied to extensive homogeneous surfaces (such as grass) under neutral atmospheric conditions and is valid under these circumstances to heights $(z)$ above $\left(z_{0}+z_{d}\right)$, where $z_{0}$ the displacement height identifies the level of the aerodynamic surface where $u(z)$ goes to zero. However, as [13], which considered the same sites presented in this paper illustrated, (2) is not applicable below $z^{*}$, the wake diffusion height

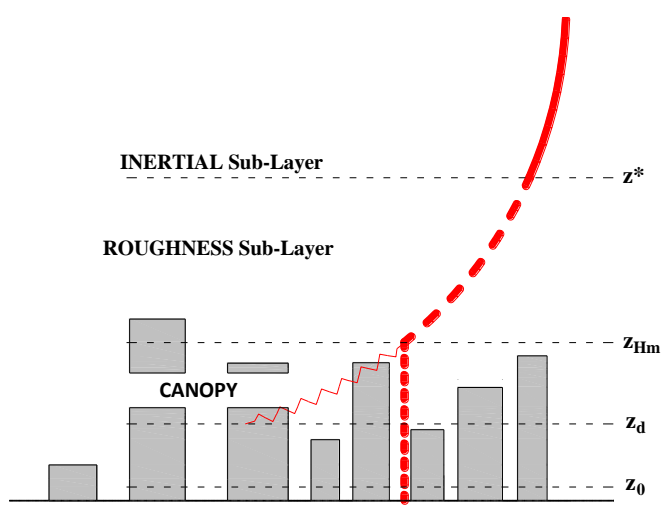

Figure 1 Urban Air-flow model in terms of the logarithmic model (2); within the roughness sub-layer $\left(\mathrm{z}^{*}<\mathrm{z}>\mathbf{z}_{\mathrm{Hm}}\right)$ wind is dominated by turbulent eddies making wind classification less reliable.

In urban environments, a distinct roughness sub-layer (RSL) between the mean building height $\left(z_{H m}\right)$ and the wake diffusion height $\left(z^{*}\right)$ is created and within the RSL, the logarithmic profile (2) is no longer applicable. From a wind resource perspective topography, the building morphology and the roughness length of the urban surface, $z_{0}$, are the significant parameters to be considered when assessing the turbulent structure of air masses [14-16]. The factitious nature of the urban topography is discussed by Fernando in [17] and fluid dynamic analyses performed in [18] describes the complexity associated with the urban topography as being the rule governing the wind resource. Indeed, this work further describes how the flow through urban RSL is highly sensitive to building morphology. An attempt to categorise types of urban 'neighbourhoods' in terms of their significant climatic effects on the overlying atmosphere is made by Stewart and Oke in which led towards a local zone classification system [19]. This 'zone' classification was employed in the positioning of the anemometry employed in this research (further described in section 3.1). In terms of the analysis presented in this paper, the anemometry at the respective locations is installed at the boundary between the RSL and the inertial sub-layer (ISL). With increased height into the ISL, the effects of the individual surface types are 'blended' and momentum and turbulence fluxes are constant with height. So the anemometry employed in this research is ideally positioned to consider turbulence.

Research has shown that the lower mean speeds are linked to the higher surface roughness lengths $z_{0}$ prevalent in urban environments $[16,20]$. The manifestation of turbulence however, is less well understood. Turbulent 
flows can be described as those in which the fluid velocity varies significantly and irregularly in both position and time [21]. While turbulently fluctuating flow impacts directly on the design of wind turbines, they also influence the productivity of power within the turbines - particularly in areas of complex morphologies. Turbulence Intensity (TI) is the most common metric to explain the turbulent effect as it is generally more useful to develop descriptions of turbulence in terms of statistical properties [22]. TI is defined in [23] as "the ratio of wind speed standard deviation to the mean wind speed, determined from the same set of measured data samples of wind speed, and taken over a specified time" and should actually be considered as the standard deviation of the wind speed $\sigma_{u}$ normalised with the mean wind speed $\bar{u}$ (3).

$$
T . I .=\frac{\sigma_{u}}{\bar{u}}
$$

The complex morphology experienced in an urban environment results in a modified flow and turbulence structure in the urban atmosphere in contrast to the flow over 'ideal or homogenous' surfaces [24]. Mertens [25] proposes that TI can be linked to the surface roughness parameter in (3).

$$
\text { T.I. }=\frac{1}{\left|\frac{z-z_{d}}{z_{0}}\right|}
$$

This equation, (4), is predicated on $\mathrm{z}$ (the observation height) being greater than the wake diffusion height $\left(\mathrm{z}^{*}\right)$, which is above the surface roughness sub-layer and into the inertial sub-layer (Figure 1). Equation (4) further suggests that there will be an increasing level of turbulence with increasing roughness and decreasing height relative to the earth's surface.

With respect to the impact on the power output of wind turbines subjected to turbulence, the majority of the available research considers utility scale systems with capacities in the MW ranges [26-29]. Cochran, [30], considered empirically linking surface roughness and the power law wind shear coefficient to turbulence manifestation. Cochran further presented a description for turbulence intensity within the lower portion of atmospheric boundary layer also based on surface roughness. His conclusions were that the (kinetic) energy available at the turbine hub height can vary by as much as $20 \%$ depending on the level of TI present at a site. In [27-29], the effect turbulence intensity has on the power curve of a turbine is that high TI exaggerates the potential output power from a turbine at moderate wind speeds (cut-in), whereas low TI undermines the potential output power at rated wind speed. Lubitz [31], considered the influence of turbulence on energy production from a Bergey XL.1 (small wind turbine). His 1Hz observations were also in agreement with [2729]. More specifically, his analysis found that low TI consistently results in reduced power output $(-2 \%)$ between $4 \mathrm{~m} / \mathrm{s}$ and $7 \mathrm{~m} / \mathrm{s}$, whereas high TI contributes to increased power output (up to $+4 \%$ ), over the same speed range. Available studies utilise measured data to provide a description of the turbulent effect and these studies are often in rural locations. However, in urban environments, unbiased high resolution wind data is 
difficult to acquire for wind speeds - and similarly, reliable and unbiased data for wind turbines (vis- à-vis localised building morphologies) in such environments is practically non-existent.

\subsection{IEC 61400-2}

The design requirements for small wind turbines in urban environments are defined by IEC 61400-2 [23]. The standard considers four different small wind turbine classes (SWT) classes (I-IV), which describe the external conditions at various sites. These external conditions relate to wind conditions as being normal or extreme. Normal wind conditions are the dominant experiences during the operation of the SWT. Turbulence and turbulence intensity in the standard is described in terms of a Normal Turbulence Model (NTM) and is utilised within the standard in deciding the suitability of a given turbine to the particular urban location. It is generally accepted that with respect to turbulence, there are two components (gusting and change of direction) that affect the performance of micro wind turbines. The gusting component is currently classified by means of the longitudinal turbulence intensity as described in [23, 32]. In ascertaining the impact of the longitudinal turbulence intensity, cosine-corrected longitudinal wind speed along the mean wind direction, is employed. Here the magnitude of the longitudinal wind speed vector is corrected against the mean wind direction of the observations within the 10-minute time frame. Figure 2 illustrates the basis for this cosine correction of wind speed observations.

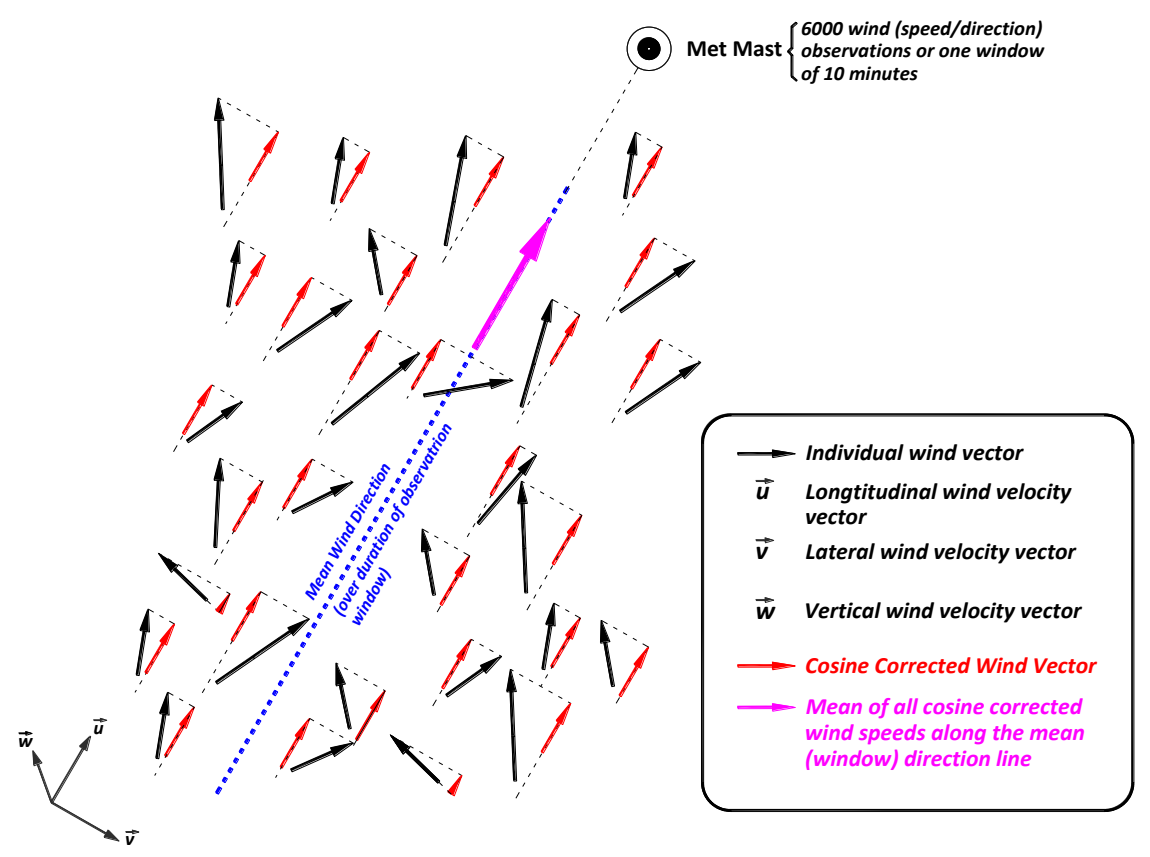

Figure 2 Cosine Correction of longitudinal wind speed observations in the $\vec{u}-\vec{v}$ plane

The IEC standard specifies the requirements for an NTM. These requirements include the characteristic value of standard deviation of the longitudinal wind velocity and a means to describe the power spectral density of the longitudinal component of turbulence, in terms of turbulence intensity as it trends asymptotically at low mean wind speeds. The standard suggests stochastic models for calculating the component power spectral density that satisfy these requirements on the basis of the turbulent velocity fluctuations being assumed random with zero mean Gaussian statistics. These stochastic models are predicated on a turbulence scale parameter which adjusts 
the power spectral calculation in terms of the height of the hub height of the wind turbine. The standard further refers to an alternative simplified approach that employs a deterministic model, but only if the turbine response to rotationally sampled wind velocity is sufficiently well damped.

The application of the standard in its current form is challenging. Urban mean wind speeds are characteristically low and at very low wind speeds, turbulence intensity - in how it is calculated - trends asymptotically. While micro/small wind turbines are designed to commence generating at low wind speeds, there will be a lack of confidence in modelling that is entirely predicated on a Normal/Gaussian distribution of wind speed. Furthermore, the NTM suggests that the utilisation of cosine corrected wind speeds based on mean wind directions (over the 10-minute sampling period). This implies that there will be outliers not considered as power producing.

\subsection{Small Wind Generation and Turbulence Modelling}

The IEC standard specifies requirements for the safety of small turbines in urban environments including design, installation, maintenance and operation. It does not present a means to determine the performance of these turbines in such turbulently saturated conditions. It is intuitively obvious that, whatever the cause, turbulence reduces the energy output from a wind turbine since turbulence dissipates energy over a larger volume (at least for an adiabatic system). It is also clear that turbulence is extremely difficult to model in a fully deterministic sense, based on the principles of fluid dynamics.

A static model (i.e. not considering the dynamic effect of the turbine yawing reaction) is described in [26] and provided in (6). There the turbine power is considered in terms of the momentary value of wind speed during a time period $T_{a}$ :

$$
v(t)=\bar{V}+u
$$

where $\bar{V}$ is the average value of $v(t)$ (taken over $T_{a}$ ) and $u$ is the gust speed. Rosen and Scheiman in [26] refer to a calculation by Christensen et al (1986), where in analysis of power curve accuracy, they assumed that the momentary value of power is given by $P_{S}(V)$, with $V$ being replaced by $v(t)(5)$. If $u$ is sufficiently small compared to $\bar{V}$, an expression, for the average power output over $\mathrm{T}_{\mathrm{a}}$ can be obtained

$$
P\left(\bar{V}, \sigma_{v}\right)=P_{S}(\bar{V}) \cdot\left\{1+\frac{1}{2}\left(\sigma_{v}^{2}\right) \cdot \frac{d^{2}\left(P_{S}(\bar{V})\right)}{d V^{2}} / P_{S}(\bar{V})\right\}
$$

where $\sigma_{v}$ is the standard deviation of the wind speed over $T_{a}$ which is defined as: 


$$
\sigma_{v}=\left\{\frac{1}{T_{a}} \int_{0}^{T_{a}}(v(t)-\bar{V}) d t\right\}^{2}=\left\{\frac{1}{T_{a}} \int_{0}^{T_{a}}(u) d t\right\}^{2}
$$

The model presented in [26] can be further developed into a quasi-steady approach to the problem whereas [33] presents a fully dynamic model taking into account both the turbulence and the turbine characteristics. However, in both cases, the second derivative as described in (6) will result in implausible power results in the transition from below rated power to rated power if this transition is sharp (as is the case for the majority of turbine technologies).

An alternative approach is proposed by Albers [34] in which a modification of a manufacturer's wind turbine power curve is presented. Albers' approach considers an idealised power curve with respect to the normal distribution model as utilised in [23]. More specifically, in [34], the wind turbine power can be simulated by considering the variation of wind speed within a window of measurement (10 minutes) as following a Gaussian distribution in terms of:

$$
\overline{P_{s i m}(u)}=\int_{u=0}^{\infty} P_{l=0}(u) \cdot f(u) d u
$$

where $u$, is wind speed $(\mathrm{m} / \mathrm{s}), f(u)$ is the wind speed distribution within the 10-minute period (Gaussian wind speeds, normally distributed about the mean) and $P_{I=0}(u)$, is the idealised wind turbine power curve, i.e. not inclusive of the affects of turbulence

Albers' hypothesis is that if the wind speed within an observation period (10 minutes) is Gaussian distributed, it is fully determinable by the average wind speed and by the turbulence intensity (or standard deviation of wind speeds within the observation period, $\sigma=T I \times \bar{u}$ ), based on (8).

$$
\overline{P_{\text {Normalised }}(u)}=\overline{P(u)}-\overline{P_{\text {sim }}(u)}+\overline{P_{\text {obs }}(u)}
$$

where $\overline{P(u)}$ is the ten minute average of measured power output and $\overline{P_{\text {sim }}(u)}$ is the simulated 10-minute average of measured power output according (8) applied in terms of the measured wind speed distribution and an assumed TI (nominally, 10\% TI is assumed). Here, the standard deviation of the turbulent wind at an assumed $\mathrm{TI}\left(T I_{\text {sim }}\right)$ and measured mean wind speed $\left(\overline{u_{\text {obs }}}\right)$ over the observation window accounts for the fact that there cannot be a zero turbulence wind $\left(\sigma_{s i m}=T I_{s i n} \times \overline{u_{o b s}}\right)$. The simulated 10-minute average of measured power output $\overline{P_{o b s}(u)}$, is similarly calculated to $\overline{P_{\text {sim } \text { IT }_{T}}(u)}$, except in the evaluation of the standard deviation here $\left(\sigma_{o b s}\right)$, the observed standard deviation $\left(\sigma_{o b s}\right)$ is evaluated by incorporating the observed TI $\left(\sigma_{o b s}=T I_{o b s} \times \overline{u_{o b s}}\right)$. 
Essentially, the manufacturer's power curve is 'idealised' by assuming 10\% TI within the derivation of the power curve and then subsequently modified to be representative of the TI within the 10 minute observation window.

The Albers approach is the springboard from which two models are considered:

1) An adaptation of the Albers approach for small wind turbines and

2) A novel approach that utilises the Weibull distribution as an alternative to the NTM.

\section{Methodology}

The following sections detail how both models are developed in the MATLAB ${ }^{\mathrm{TM}}$ programming environment.

\subsection{Wind Observations}

Observations are made at two urban locations in Dublin, Ireland. St. Pius X National (Girls) School (SUB1), located in Terenure, Dublin 6W (53 $\left.20^{\circ} 15.96^{\prime} \mathrm{N}, 6^{0} 18^{\prime} 19.02^{\prime \prime} \mathrm{W}\right)$ and Dublin City Council Buildings (URB1), in Marrowbone Lane, located in Dublin $8\left(53^{0} 20^{\prime} 15.96^{\prime \prime} \mathrm{N}, 6^{0} 17^{\prime} 10.27^{\prime \prime} \mathrm{W}\right.$. URB1 is located closer to the city centre than SUB1 and is therefore more urbanised with a higher associated roughness length. This site is also characterised by a higher building density in comparison to SUB1. As URB1 is closer to the city centre, the buildings consist mostly of office blocks and high-rise residential buildings. Buildings in the area often reach heights of $20 \mathrm{~m}$ and beyond with morphological complexities located at all angles relative to the anemometer used to record the wind velocity data. SUB1 has a more consistent building morphology and the anemometer is surrounded by a relatively lower average building height that consists mostly of two-storey residential buildings and vegetation which is also at similar heights. Figure 3, which is modified from [13], presents a context for both sites, where detailed analysis of the wind resource in an urban environment is considered
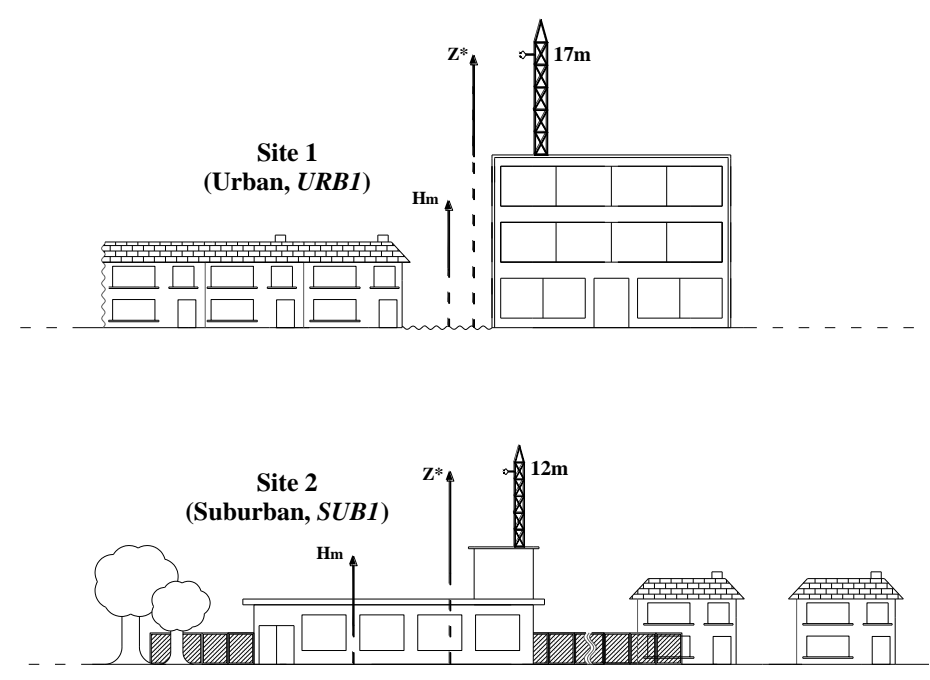

Figure 3 Relative context of wind observation locations (source: [13]).

At both sites, high-resolution wind speed measurements are taken with a Campbell Scientific CSAT3 threedimensional sonic anemometer [35]. The observations are at $10 \mathrm{~Hz}$ at an associated resolution-between 0.5 and 
$1.0 \mathrm{~mm} / \mathrm{s}$, with data that includes date and time-stamp, wind-speed, wind-direction and standard deviation. The CSAT3 measures wind speed employing a right handed orthogonal coordinate system. Three orthogonal wind components, which relate to the three dimensions in space, are each measured. Wind entering straight into the anemometer is from the $\mathrm{x}$-direction giving wind velocity component $\mathrm{u}_{\mathrm{x}}$; wind approaching from the left of the anemometer is from the $y$-direction giving wind velocity component $\mathrm{u}_{\mathrm{y}}$; and, wind advancing upwards from the ground is from the $\mathrm{z}$-direction generating wind velocity component $\mathrm{u}_{\mathrm{z}}$. Measurements of this field are taken over a 40 day period from 4/4/2012 to 15/5/2012. Consistent with [23], a 10 minute sampling period bench mark, this period is used on a moving window basis, each window consisting of 6000 samples (10 minutes at $10 \mathrm{~Hz})$. Data was subject to quality control: $i$ ) data are removed if the period of 10 minutes is incomplete; $i i)$ erroneous data are removed; iii) if TI is calculated to be $>100 \%$, the TI for the observation period is set to $100 \%$ (note, this control is with respect to the turbine power modelling only; this constraint is not applicable in the discussion in section 5)

\subsection{Albers Approximation}

The methodology uses a manufacturer's wind turbine power curve that is modified on the basis of varying TI and wind speed so that the turbine power output for each 10 minute summary of observed TI and mean wind speed, through a 'look-up table', can be obtained. The turbine power curve employed in this paper was acquired from HOMER ${ }^{\mathrm{TM}}$ (Hybrid Optimisation Model for Electric Renewables (version 2.81) as developed by the US National Renewable Energy Laboratory (NREL) [36] and is indicative of a standard manufacturer's power curve. The specific turbine characteristic (Skystream 3.7, 2.4kW) is decomposed within MATLAB into a polynomial equation that can be applied to any set or subset of wind speeds ${ }^{1}$; subject to limiting the power curve in terms of both cut-in wind speed and for wind speeds in excess of the power curve's maximum specified wind speed.

Figure 4 illustrates how the Skystream power curve is applied in the analyses, with equation (10), providing a $10^{\text {th }}$ order polynomial description, of the turbine power curve $\left(P_{P}\right.$ $(u))$, in terms of wind speed $(u)$, (as derived in MATLAB $\left.{ }^{\mathrm{TM}}\right)$.

\footnotetext{
${ }^{1}$ In terms of the polynomial description of the wind turbine characteristic, the cut-in wind speed $\left(\mathrm{u}_{\text {cut-in }}\right)$ is considered to be $1.5 \mathrm{~m} / \mathrm{s}$.
} 


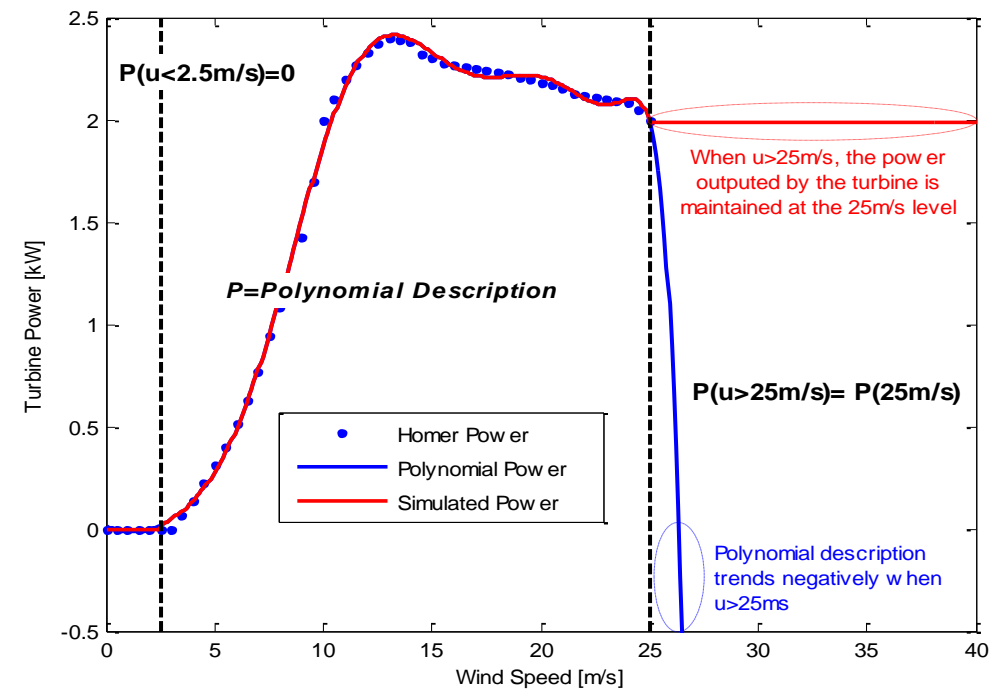

Figure 4 Illustrating the modification to the Skystream $2.5 \mathrm{~kW}$ Wind Turbine Power curve as employed in both models

$$
\begin{aligned}
P_{\text {Power-Curve }}(u)=-( & \left(1.62 \times 10^{-10}\right) u^{10}+\left(1.89 \times 10^{-8}\right) u^{9}-\left(9.17 \times 10^{-7}\right) u^{8}+\left(2.38 \times 10^{-5}\right) u^{7} \\
& -\left(3.55 \times 10^{-4}\right) u^{6}+\left(3.07 \times 10^{-3}\right) u^{5}-\left(1.50 \times 10^{-2}\right) u^{4}+(0.04) u^{3} \\
& -\left(3.49 \times 10^{-2}\right) u^{2}+\left(1.66 \times 10^{-2}\right) u-\left(9.07 \times 10^{-3}\right)
\end{aligned}
$$

The Albers approach, which quantifies the degradation of power performance of a wind turbine [34], is thus modified so as to predict the power performance based on raw wind resource observations. Employing an approximation to the Albers' approach, the turbine characteristic can be normalised to any level of TI as illustrated in Figure 5. The curves derived are consistent with observations [27, 28, 31].

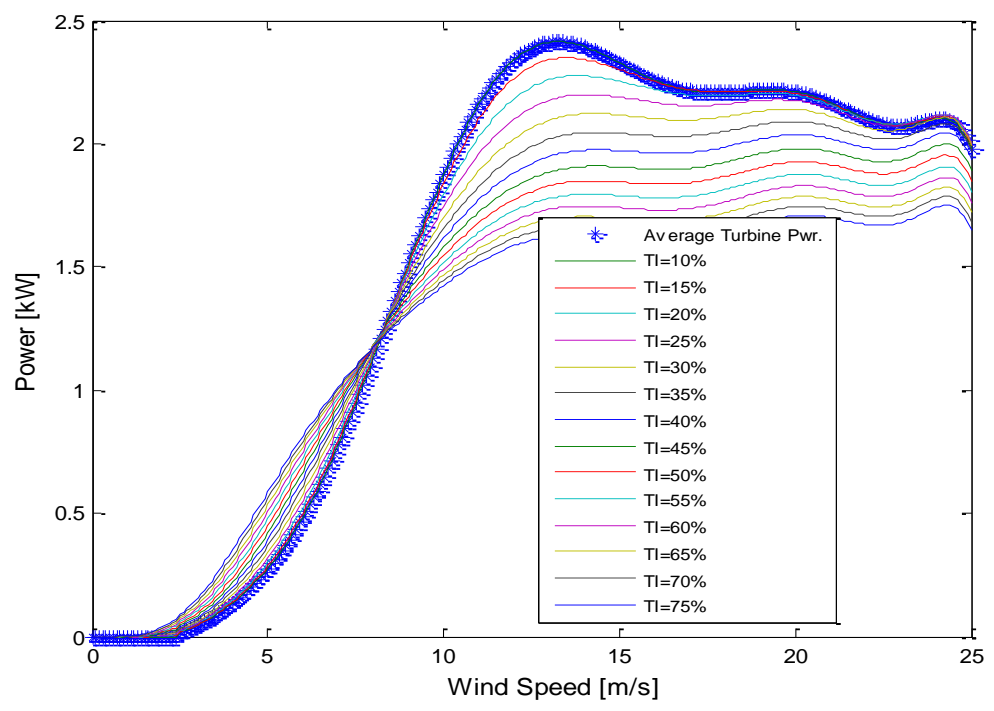

Figure 5 Albers Approximation of the Skystream 3.7 (2.4kW) Power curve in terms of varying TI and wind speed. 
A tabulation of the turbine's turbulence modified output power for the power curve wind speed range and range of practicable TI percentages is thereby facilitated. The procedure, which is implemented in MATLAB $7^{\mathrm{TM}}$ is presented in Figure 6.

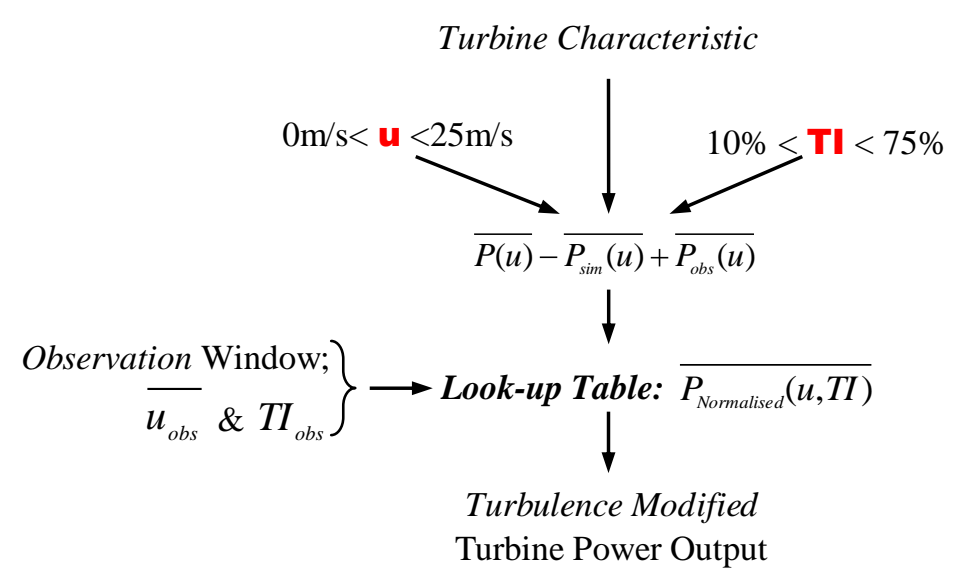

Figure 6 Flow Chart describing the Albers Approximation as utilised to derive the normalised turbine output in a turbulent environment.

The Albers Approximation considers turbine output and each wind speed observation window in three ways. The average power output from the turbine is calculated based on the mean of the 6000 wind speed data-points ${ }^{2}$. This average wind speed is applied to (10) and the average power is calculated. This value of turbine power is based on an ideal power curve with the implications of turbulence removed. The power curve is therefore modified (in terms of (8)) to be representative of such effects by applying a Gaussian distribution with a mean wind equal to the mean of the 6000 data-points and a standard deviation based on a speculative TI. In the absence of specifics, the turbine characteristic is modified on the basis of $\mathrm{TI}=10 \%$. Finally, the effect of the observed TI is applied to the turbine curve (again though (8)) by employing a Gaussian distribution with a standard deviation based on observations (6000/window). These calculations, collectively contained in (9) are facilitated through one look-up table. This approach however, loses validity at lower wind speeds as negative longitudinal wind speeds (derived through the application of a Gaussian distribution in the methodology) will arise, e.g. wind speeds with a mean wind of $1 \mathrm{~m} / \mathrm{s}$ and a TI value of $75 \%$. However - as will be demonstrated the methodology is robust for higher wind speeds incorporating high TI. The question arises: Is there an optimal frequency distribution other than a normal distribution that could more accurately represent lower wind speeds?

Given the potential issues with the Albers approach at low wind speeds other probability density functions (PDF) should be considered. Archer and Jacobsonp [37] suggest that wind speed PDFs are not static in nature and that they are dependent on the surface conditions. Based on data from 1327 surface stations and 87 soundings in the U.S. for the year 2000, the PDF of wind speed with respect to turbulence and wind speed can be characterised as in Table 1 .

\footnotetext{
${ }^{2} 10 \mathrm{~Hz}$ sampling implies 6000 samples in 10 minutes
} 
Table 1 Turbulence and Wind Speed PDF Classification inferred from hourly records from 1327 surface stations and 87 soundings in the U.S. for the year 2000

\begin{tabular}{rlr|c|c|} 
& \multicolumn{2}{c}{$\begin{array}{c}\text { High Turbulence } \\
\text { (Urban/suburban) }\end{array}$} & \multicolumn{1}{c}{$\begin{array}{c}\text { Med Turbulence } \\
\text { (Suburban/Rural) }\end{array}$} & \multicolumn{1}{c}{$\begin{array}{c}\text { Low Turbulence } \\
\text { (Rural/Off-shore) }\end{array}$} \\
\cline { 3 - 5 } Low & $\bar{u}$ & Logarithmic PDF & Logarithmic / Rayleigh PDF & Rayleigh PDF \\
\cline { 2 - 4 } Medium & $\bar{u}$ & Logarithmic/Rayleigh PDF & Rayleigh PDF & Rayleigh / Gaussian PDF \\
\cline { 2 - 4 } High & $\bar{u}$ & Rayleigh PDF & Rayleigh / Gaussian PDF & Gaussian PDF \\
\cline { 3 - 5 } & &
\end{tabular}

If we consider a Weibull distribution in the same context as the NTM the effects are similar at higher wind speeds to that of the normal distribution model. The fundamental difference however, is that the Weibull distribution gets progressively more logarithmic at lower mean wind speeds for higher values of TI. Figure 7 illustrates how a Weibull distribution with varying shape and scale can approximate the criteria presented in Table 1.

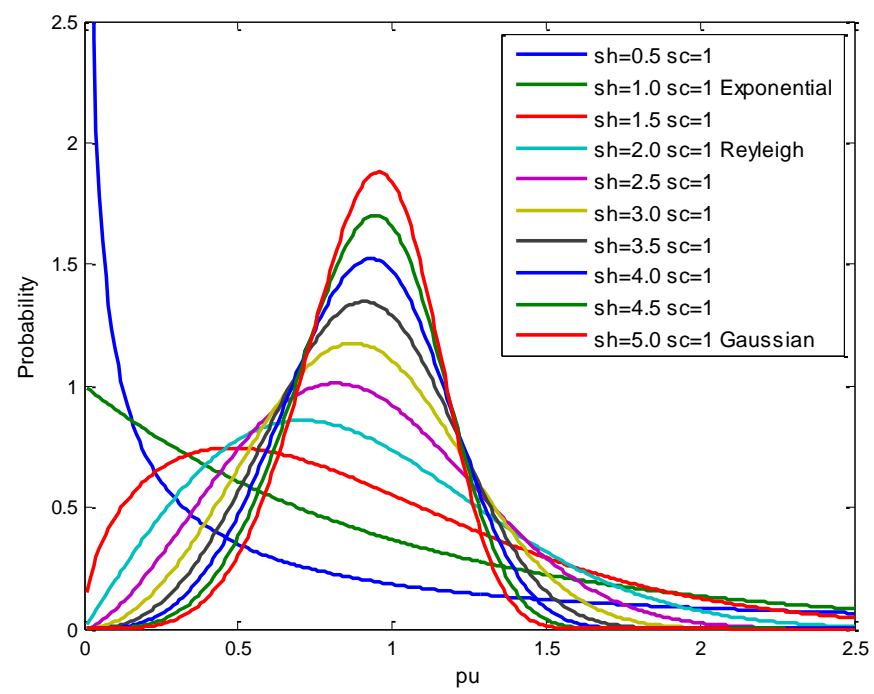

Figure 7 Weibull Probability Distribution with varying shape parameters representing the exponential, logarithmic and Gaussian probability distributions

\subsection{Weibull Approximation}

The Weibull distribution is commonly used to describe wind and wind energy [7-9] and this function has been shown to give a good fit to measured wind speed data [38]. The Weibull distribution function is described in (11).

$$
P\left(u<u_{i}<(u+d u)\right)=P(u>0) \cdot\left(\frac{k}{c}\right) \cdot\left(\frac{u_{i}}{c}\right)^{k-1} \cdot e^{\left(u_{i} / c\right)^{k}} d u_{i}
$$

The Weibull scaling factor, $c$, has the same units describing wind speed; $\mathrm{k}$, represents the Weibull shape parameter; $u_{i}$ is a particular wind speed; du is an incremental wind speed and $P\left(u<u_{i}<(u+d u)\right)$ is the probability that the wind speed is between $u$ and $(u+d u)$ [39]. The Rayleigh distribution is a special case of the Weibull distribution in which the shape parameter, $k$, has a value of 2.0. 
The Weibull normalized power is calculated by implementing Weibull PDFs that meet the same sample criteria for mean wind speed and TI as that measured over the observation window. An average power value is calculated based on 6000 randomly generated data-points and the modelled Weibull PDF(s) in terms of the specific turbine characteristic (Skystream 3.7). Unlike the Albers approximation, the Weibull approximation has two stages, which are summarised in Figure 7. Multiple Weibull PDFs are created by varying shape and scale parameters. The shape factor is varied from 0.05 to 30 in 0.01 increments in conjunction with varying scale factors, from 0.05 to 15 in 0.01 increments (4.6 million PDFs). These PDFs are subsequently interrogated against practical wind speed and TI references, i.e. the best fit for a speed range from $0: 25 \mathrm{~m} / \mathrm{s}(0.1 \mathrm{~m} / \mathrm{s}$ increments) and TI (10\% to $75 \%$ in 5\% increments). For each of the (4.6million) generated Weibull distributions, corresponding mean wind speed and standard deviation values are recorded. These values are formatted to a resolution of $0.1 \mathrm{~m} / \mathrm{s}$ wind speed and TI of $5 \%$ on the basis of best fit. The 'best fit' is achieved by method of least squares difference between the generated values and the formatted vales. A table of shape and scale parameters, in terms of mean wind speed and TI, is compiled and each entry is applied to a Weibull distribution to derive a simulated wind speed distribution. These Weibull simulated wind speed distributions are then applied to the polynomial description of the power curve. In this way, the table is enhanced to describe the turbine power in terms of a polynomial representation of the power curve, based on mean wind speed and TI.

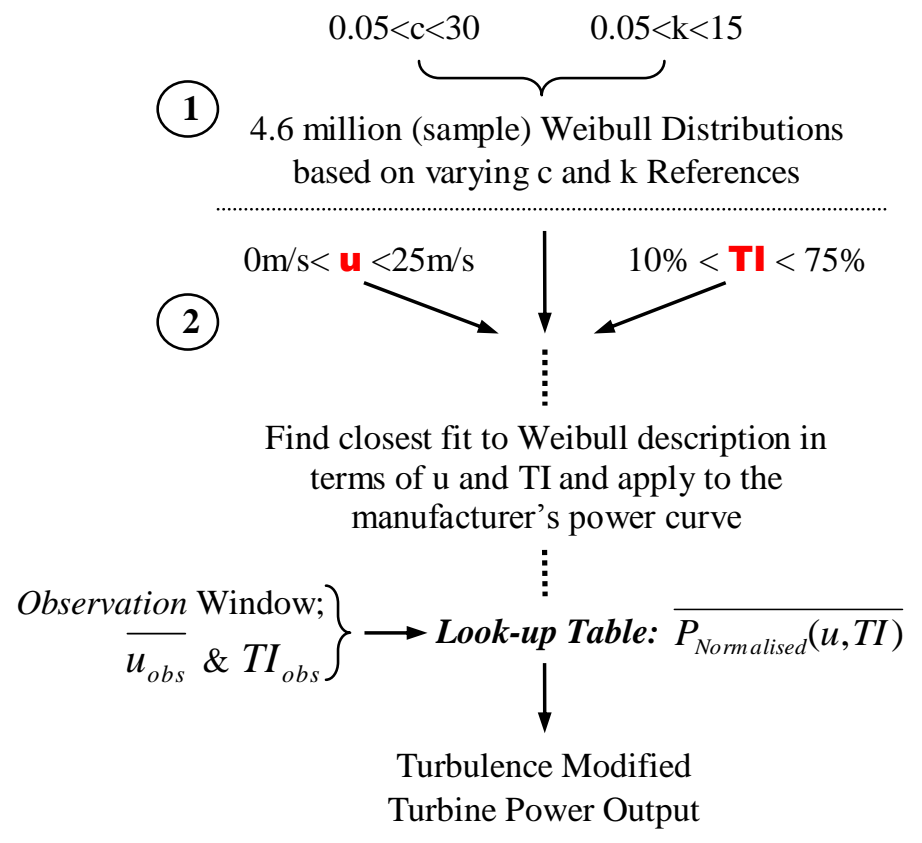

Figure 8 Flow Chart describing the Weibull Approximation as utilised to derive a turbine output estimate in a turbulent environment.

Figure 9 illustrates the Skystream 3.7 power curve normalised to the range of practicable TI values (\%). The stochastic nature of the power curves is what is currently achievable with best fit mean and TI parameters as there is a certain amount of rounding evident. A look-up table (similar to the Approximated Albers methodology) presenting the turbine output power with respect to varying TI and wind speed is thus derived. 


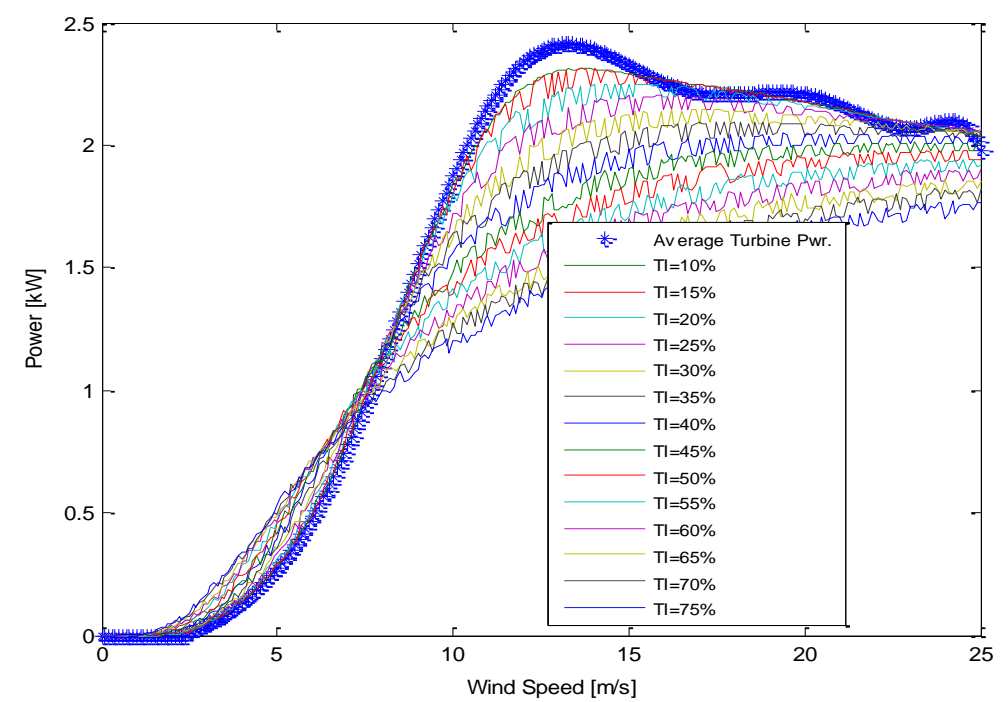

Figure 9 Weibull Approximated Skystream 3.7 (2.4kW) Power curves in terms of varying TI and wind speed.

\section{Results}

Over a 40 day period from 4/4/2012 to $15 / 5 / 2012,10 \mathrm{~Hz}$ measurements are organised into 10 minute observation windows. As illustrated in Table 2, SUB1 and URB1 respectively contained $5.0 \%$ and $7.94 \%$ of erroneous observation 'windows', Each window considers three power measurements: the Albers approximation $\mathrm{P}_{\text {norm }}$, the Weibull approximation, $\mathrm{P}_{\text {weib }}$ and the average power over the window, $\mathrm{P}_{\text {mean }}$, which is calculated by considering the turbine characteristic with respect to the mean speed over the observation window. $\mathrm{P}_{\text {mean }}$, is the industry norm for data logging of power output from wind turbines. Each of these calculations are benchmarked against the absolute power, $\mathrm{P}_{\mathrm{abs}}$, which is the average of individualised (6000) calculations of power over the observation window and represents the truest measure of generated power by the turbine. Figure 10 illustrates scattergram comparisons of the three turbine output power measurements $\left(\mathrm{P}_{\text {mean }}, \mathrm{P}_{\text {norm }}\right.$ and $\left.\mathrm{P}_{\text {weib }}\right)$ with respect to $\mathrm{P}_{\mathrm{abs}}$ at URB1, (a) and SUB1, (b), respectively. An ideal comparison for either of the three calculation methodologies would give a 1:1 slope ratio $(\mathrm{m}=1)$ with an associated intersection and correlation of 0 and 1 respectively. This comparison shows that there is a strong correlation between the Albers $\left(\mathrm{P}_{\text {norm }}\right)$ and Weibull $\left(\mathrm{P}_{\text {weib }}\right)$ approximations to the absolute power generated over the observation window $\left(\mathrm{P}_{\mathrm{abs}}\right)$. The average power $\left(\mathrm{P}_{\text {mean }}\right)$ at both locations is shown in general, to underestimate at lower wind speeds, whereas at higher wind speeds, there is a potential to overestimate. 
(a)

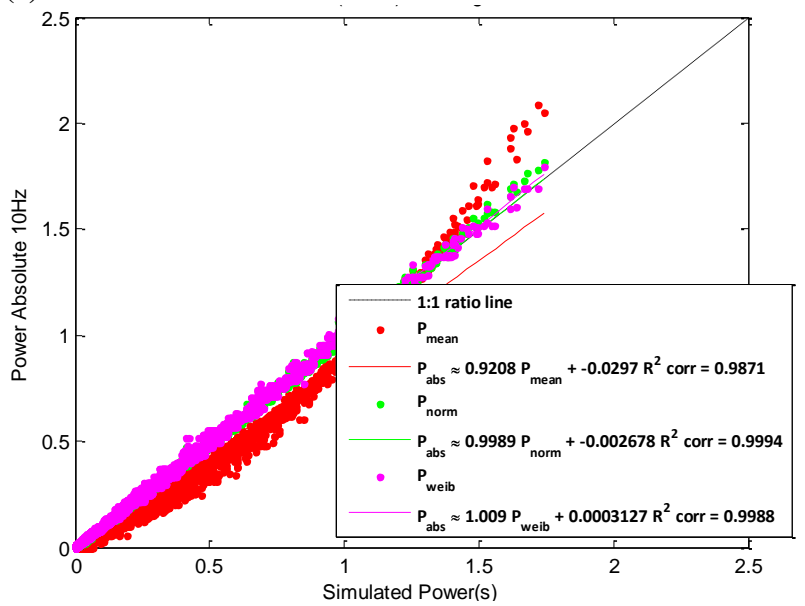

(b)

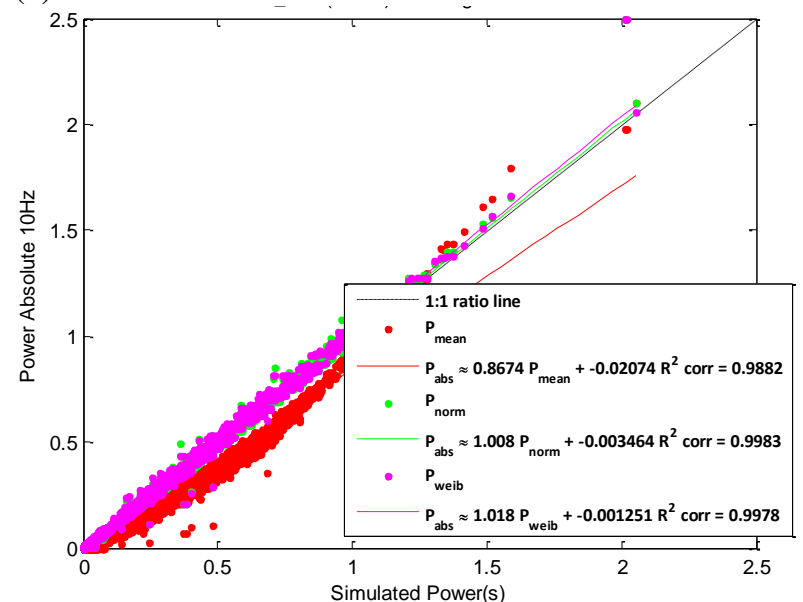

Figure 10 Scattergram comparisons of $P_{\text {mean, }} P_{\text {norm }}$ and $P_{\text {weib }}$ with respect to $P_{\text {abs. }}$. For both URB1 (Figure 9(a)) and SUB1 (Figure 9(b)).

The comparison presented in Figure 10 is further considered to establish if there is an underlying trend in the power prediction methodologies and whether the simulated models under or overprescribe with respect to $\mathrm{P}_{\mathrm{abs}}$. Figure 11 presents a cumulative sum of differences that occur throughout the full set of 40 days of data with Figure 11 (a) illustrates this trend analysis for URB1 and Figure 11 (b) illustrates similar for SUB1.

(a)

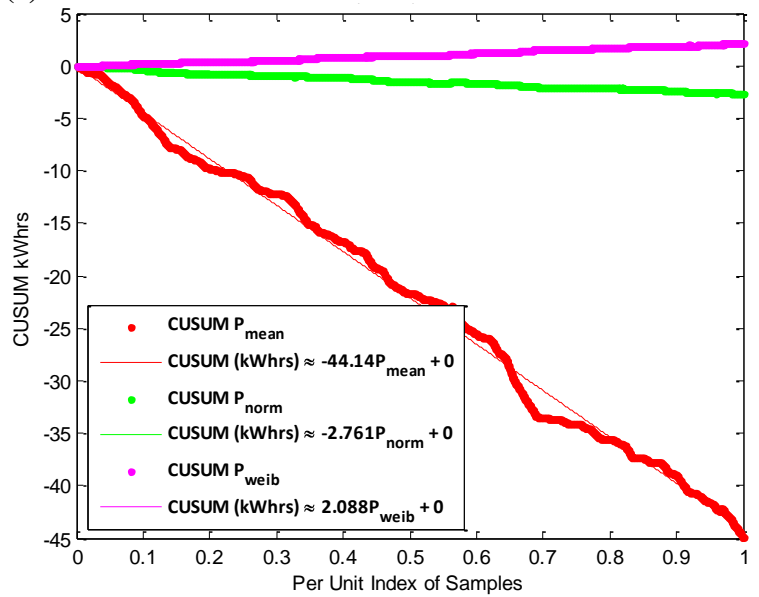

(b)

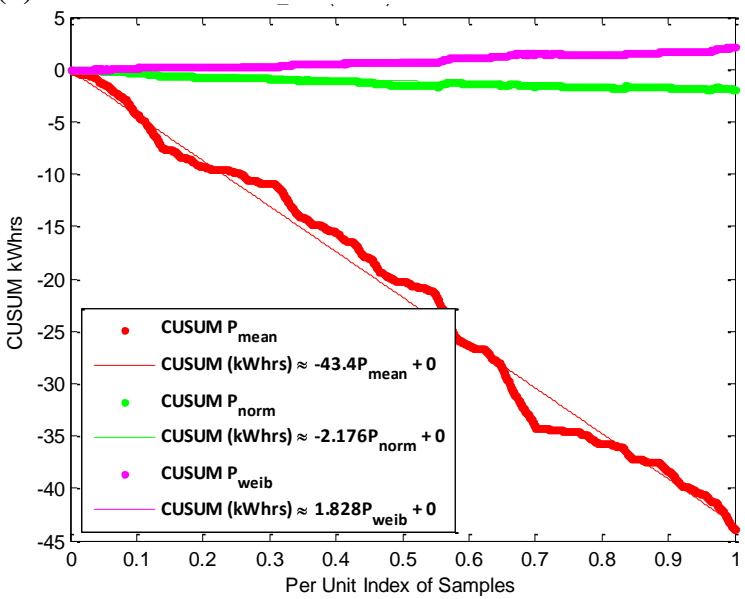

Figure 11 The cumulative error for each of the calculated power models $\left(P_{\text {mean }}, P_{\text {norm }}\right.$ and $\left.P_{\text {weib }}\right)$ for both sites (URB1 (a) and SUB1 (b)).

It is clearly evident that for both sites, $\mathrm{P}_{\text {weib }}$ and $\mathrm{P}_{\text {norm }}$ are virtually horizontal, with only a slight over prediction derived using $\mathrm{P}_{\text {weib }}$ and under-prediction using $\mathrm{P}_{\text {norm }}$ cumulatively derived over the 40 days of observations. This strongly implies that both models are consistent with the $\mathrm{P}_{\mathrm{abs}}$ measurements and are accurate with respect to representing practically, the effect of turbulence on the wind turbine. Table 2 presents the total energy (kWhr) derived from each of the methodologies and the results are consistent with Figure 11. 
Table 2 Tabulation of cumulative energy using the power estimation models in context with the absolute power calculated over the observation windows.

\begin{tabular}{|c|c|c|c|c|}
\hline & \multicolumn{2}{|r|}{ SUB1 } & \multicolumn{2}{|r|}{ URB1 } \\
\hline $\begin{array}{r}\text { Erroneous } \\
\text { Data/Observation- } \\
\text { Windows (\%) }\end{array}$ & \multicolumn{2}{|r|}{5.0} & \multicolumn{2}{|r|}{7.94} \\
\hline $\mathrm{u}_{\mathrm{MEAN}}[\mathrm{m} / \mathrm{s}]$ & \multirow{2}{*}{\multicolumn{2}{|c|}{$\frac{3.41}{1.70}$}} & \multicolumn{2}{|r|}{3.74} \\
\hline $\mathrm{U}_{\mathrm{STD}}[\mathrm{m} / \mathrm{s}]$ & & & & 1.73 \\
\hline $\begin{array}{c}\text { Prediction } \\
\text { Methodology }\end{array}$ & $\begin{array}{c}\text { Total } \\
\text { Power } \\
\text { predictions } \\
\end{array}$ & \multirow{2}{*}{$\begin{array}{c}\text { Relative error } \\
\left\{\frac{\sum\left(P_{a b s}\right)-\sum\left(P_{i}\right)}{\sum\left(P_{a b s}\right)}\right)\end{array}$} & $\begin{array}{c}\text { Total } \\
\text { Power } \\
\text { predictions } \\
\end{array}$ & \multirow{2}{*}{$\begin{array}{c}\text { Relative error } \\
\left\{\frac{\sum\left(P_{a b s}\right)-\sum\left(P_{i}\right)}{\sum\left(P_{a b s}\right)}\right.\end{array}$} \\
\hline$\sum\left(P_{a b s}\right) \mathrm{kWh}$ & 181.82 & & 218.77 & \\
\hline$\sum\left(P_{\text {mean }}\right) \mathrm{kWh}$ & 137.86 & $-24.2 \%$ & 173.90 & $-20.5 \%$ \\
\hline$\sum\left(P_{\text {norm }}\right) \mathrm{kWh}$ & 179.93 & $-1.0 \%$ & 216.04 & $-1.3 \%$ \\
\hline$\sum\left(P_{\text {weib }}\right) \mathrm{kWh}$ & 183.94 & $1.2 \%$ & 220.94 & $1.0 \%$ \\
\hline
\end{tabular}

If the cumulative error characteristic is considered (in terms of a relative error calculation illustrated in Table 2), the probability of an error being below a given $\mathrm{kW}$ rating for a given simulated model, Figure 12illustrates that once again the $\mathrm{P}_{\text {weib }}$ model for both sites has over $90 \%$ of its error within $50 \mathrm{~W}$ of the $\mathrm{P}_{\mathrm{abs}}$ at both sites.

(a)

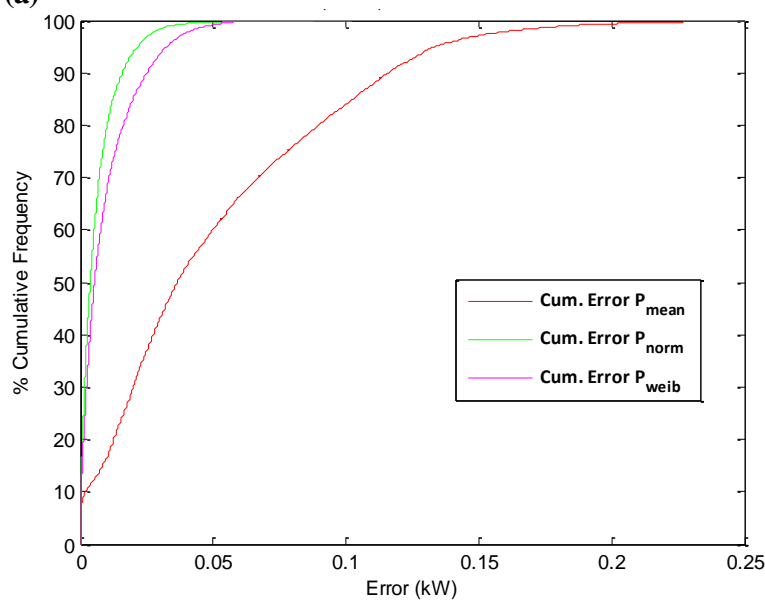

(b)

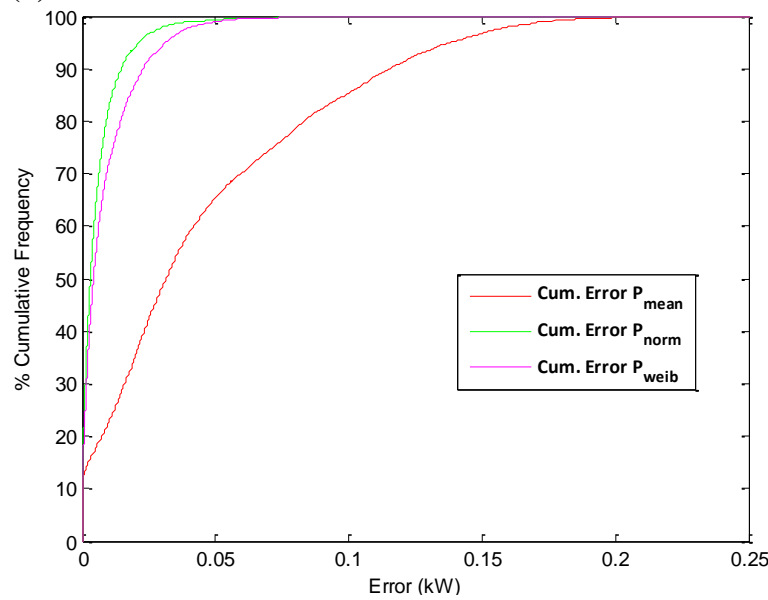

Figure 12 The cumulative error characteristic for each of the power prediction models at both URB1 (a) and SUB1 (b), highlighting the accuracy of both models.

Finally, the mean absolute error (MAE) between the power estimation models and the absolute power over the range of observation windows is considered. The MAE is the average, over each binned wind speed, of the absolute values of the differences between $\mathrm{P}_{\mathrm{abs}}$ and the corresponding modelled power $\left(\mathrm{P}_{\text {mean }}, \mathrm{P}_{\text {norm }}\right.$ and $\left.\mathrm{P}_{\text {weib }}\right)$, thereby measuring the average magnitude of the errors in each wind speed bin for each model.

$$
M A E=\frac{1}{n} \sum_{i=1}^{n}\left|P_{a b s}-P_{\text {Model }}\right|
$$




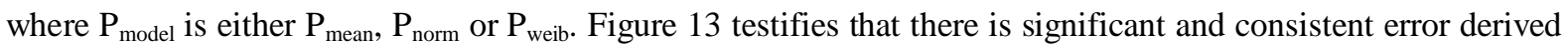
with respect to $\mathrm{P}_{\text {mean }}$. The albers and Weibull approximations $\left(\mathrm{P}_{\text {norn }}\right.$ and $\left.\mathrm{P}_{\text {weib }}\right)$ perform reasonably well across the spectrum of wind speeds with a tendency to introduce error $(<75 \mathrm{~W})$ at high wind speeds. It is important to note that such wind speeds would be uncharacteristic across urban environments.

(a)

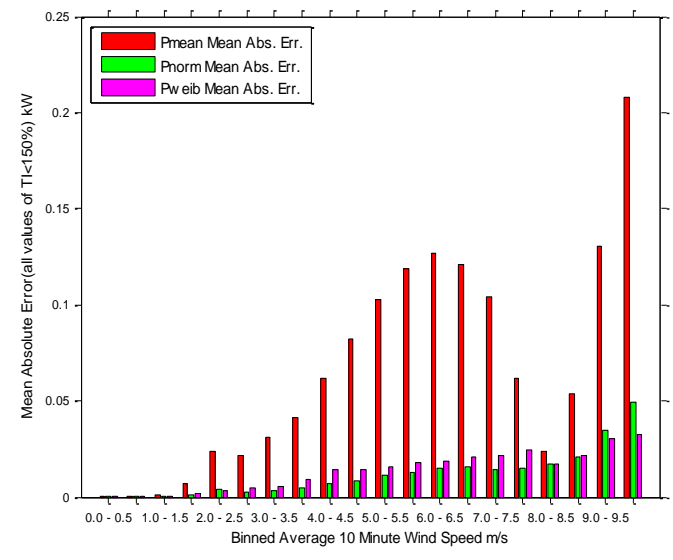

(b)

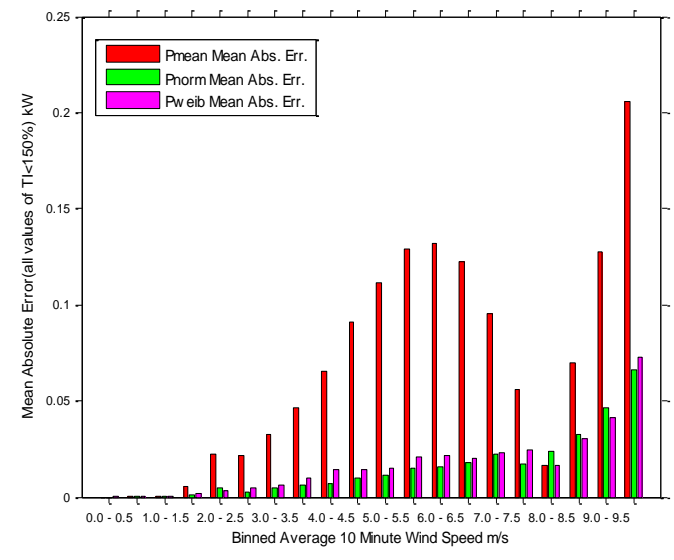

Figure 13 MAE comparisons of the power estimation models with respect to $P_{\text {abs }}$ at both URB1 (a) and SUB1 (b)

\section{Discussion}

The analysis in the preceding section has shown that Gaussian and Weibull probabilistic statistics, considered in terms of TI observations, can provide an accurate means to estimate the electrical power output of a wind turbine at both a suburban and urban location. As the analyses employed anemometry installed at specific locations representative of their respective environments, with said observations within neutral atmospheric conditions, an obvious progression would be to characterise TI in terms of surface characteristics across all types of urban location. Table 3 summarises first order estimates of $d$ and $z_{0}$ (displacement height and surface roughness length respectively) for the urban context. These estimates are collated within different categories of cityscape (based on a combination of measurement and informed speculation) as presented by Grimmond and Oke in their work pertaining to the aerodynamic properties of urban areas, [40]. These estimates were utilised in developing a local climate zone classification system [19], where the diversity of landscape/topography is collated as inter-classifications under the urban umbrella. Mertens [25], further observed that TI is proportional to $z_{0}(4)$, but this equation requires $\mathrm{z}>\mathrm{Z}^{*}$, the wake diffusion height. The observations considered here are at the boundary between the RSL and ISL and as such, application of (4) to derive TI is not appropriate. Nor is it a viable approach for the majority of urban wind turbines when one considers the likely hub heights for these technologies. An objective for further research therefore, is to define the impact on turbine power output based on urban surface roughness classification by linking it to surface roughness length. 
Table 3 Typical roughness of homogeneous zones in urban areas, ordered by height and density (excerpted from [40])

\begin{tabular}{|c|c|c|c|}
\hline Urban Surface Form & $\mathrm{Z}_{\mathrm{H}}(\mathrm{m})$ & $\mathrm{z}_{\mathrm{d}}(\mathrm{m})$ & $\mathrm{z}_{0}(\mathrm{~m})$ \\
\hline \multicolumn{4}{|l|}{ Low Height and Density } \\
\hline $\begin{array}{l}\text { Residential - one or two-storey single houses, gardens, small trees. } \\
\text { Mixed houses and small shops. Warehouse, light industrial, few } \\
\text { trees }\end{array}$ & $5-8$ & $2-4$ & $0.3-0.8$ \\
\hline \multicolumn{4}{|l|}{ Medium Height and Density } \\
\hline $\begin{array}{l}\text { Residential - two and three-storey large or closely spaced, } \\
\text { semidetached and row houses, large trees. Less than five-storey } \\
\text { blocks of flats with open surroundings. Mixed - houses with shops, } \\
\text { light industry, churches, schools. }\end{array}$ & $7-14$ & $3.5-8$ & $0.7-1.5$ \\
\hline \multicolumn{4}{|l|}{ Tall and High Density } \\
\hline $\begin{array}{l}\text { Residential - closely spaced < six-storey row and block buildings or } \\
\text { major facilities (factory, university, etc.), town centre. }\end{array}$ & $11-20$ & $7-15$ & $0.8-1.5$ \\
\hline $\begin{array}{l}\text { Urban core or suburban nodes with multistory tower blocks in } \\
\text { dense urban surroundings. Major institutional complexes }\end{array}$ & $>20$ & $>12$ & $>2.0$ \\
\hline
\end{tabular}

According to Table 3, and with respect to the two locations in Dublin, SUB1 is characterised as 'Low Height and Density', whereas, URB1 is characterised as 'Medium Height and Density' and both sites have distinctive and different surface roughness lengths. Figure 14 illustrates the average filtered TI over wind speed bins for the 40 days observed at both sites. Here the TI level is filtered on the basis of wind speed and potential for spurious TI. In the event of extremely high wind speed or exceptionally low wind speeds, in the equation describing TI (equation (3)), asymptotic values are derived. In the context of this research, said occurrences are treated as anomalies.

As Metens describes in (4), higher surface roughness lengths $\left(z_{0}\right)$, will derive a greater the level of TI Relating TI to surface roughness requires an ability to trend TI across the spectrum of practical wind speeds. An obvious way to consider this is with respect to average TI in wind speed bins. Figure 14 (a) and (b) illustrate average TI is binned with respect to binned wind speeds for URB1 and SUB1 respectively, with average TI per wind speed bin superimposed for reference. First of all, the figure clearly illustrates that both sites have different wind speed distributions and this will affect how mean TI can be interpreted. This wind speed distribution inconsistency will bias the average TI so that above $3 \mathrm{~m} / \mathrm{s}$, the average TI observed at SUB1 appears to be greater than observed at URB1, contrary to the position that at sites with increased surface roughness lengths, TI will be higher. Also, the number of observations at both sites within each wind speed bin will introduce biasing of TI averaging. Furthermore, the proliferation of unrealistically high TI at low wind speeds $(0-1 \mathrm{~m} / \mathrm{s})$ as illustrated in Figure 14 will contribute to this biasing effect. These abnormalities have the effect to skew the average TI. The same can be said for any TI 'outliers' within other wind speed bins along the practicable wind speed spectrum. 
(a)

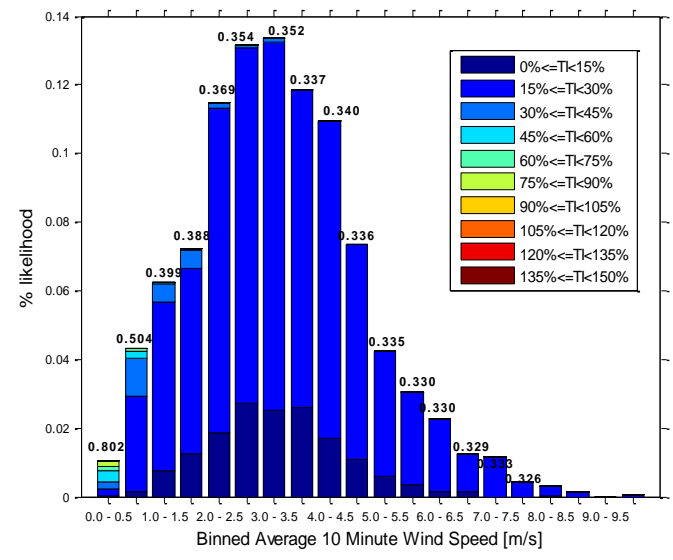

(b)

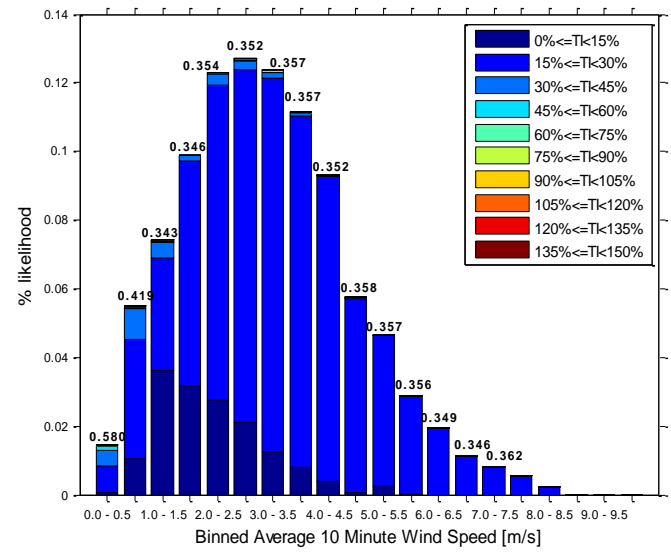

Figure 14 Binned TI (15\% bins) with respect to binned wind speed $(0.5 \mathrm{~m} / \mathrm{s}$ bins) representing observations at both urban locations (URB1 (a) and SUB1 (b)). TI is filtered so that only TI $<150 \%$ are considered. Average TI per wind speed bin is also superimposed.

Speculative trending is considered on the basis of the lower wind speeds where TI and turbulence have the most effect and where biasing within the 40 days of observations were least prevalent. This concept leads to Figure 15 , where said trending attempts to relate the different surface roughness characteristics describing both URB1 and SUB 1 respectively. This trend is speculative such empirical linkage requires further consideration and cross referencing to alternative wind speed observations at different sites with different surface roughness characteristics.

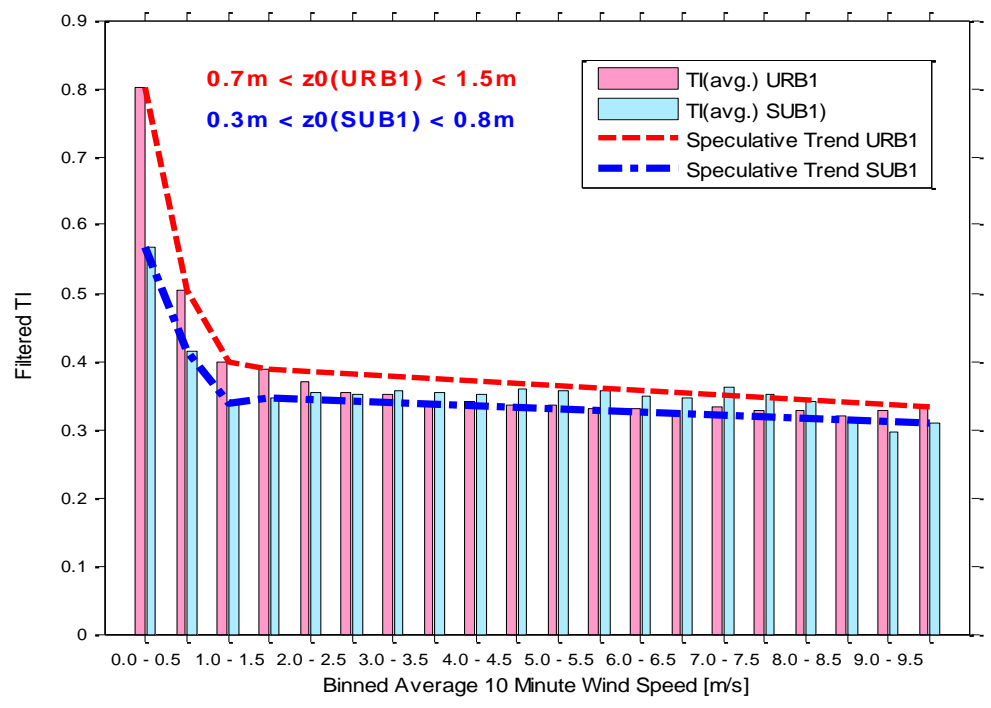

Figure 15 Average TI in terms of binned wind speeds at both urban locations (SUB1 and URB1). The TI bins are filtered so that only $\mathrm{TI}<150 \%$ are considered. Trend lines are included as speculative reference.

\section{Conclusions and Future Work}

It is well understood that turbulence has a detrimental mitigating effect on wind turbine productivity and that in urban environments, within complex building geometries and morphologies, turbulence will be implicit within any available wind resource. However, in a context of renewable energy and energy sustainability, combined 
with increasing population migration towards urban centres, all means to harness wind energy should be explored.

There are two aspects to understanding turbulent wind within these environments. First of all there are the decisions pertaining to installation so that optimal performance can be achieved; hub-height with respect to proximity/influence of adjacent buildings/obstructions. Secondly an appreciation/quantification of how turbulence affects the productivity of a wind turbine is required so that installers can be informed on the basis of installation location. The latter has been the focus of this paper, with the goal of predicting turbine productivity based on turbulence intensity.

Two mathematical models have been proposed. The first, an adaptation of Albers' work [34], and the second, employs an alternative to the Albers' Gaussian statistics approach to derive indicative TI by using the Weibull distribution. The structure of both models is similar with the exception that the Weibull approximation does not require the wind turbine characteristic, whereas the Albers approximation is based on knowledge of an accurate power curve. Both models were benchmarked using the Skystream $3.7(2.5 \mathrm{~kW})$ wind turbine, which is representative of commercially available technologies in similar ranges.

Two locations within Dublin City, Ireland, characterised as sub-urban (SUB1) and urban (URB1), were employed to investigate both models over a period of 40 days (from 4/4/2012 to 15/5/2012). At both locations, high resolution (sonic) anemometry samples the wind resource at $10 \mathrm{~Hz}$ at a height of about 1.5 times the average building height at both locations. Such a height is specifically chosen to be on the border of the roughness and inertial sub-layers and as such represents an ideal representation of where, intuitively, small wind turbine technologies are likely to be installed. Benchmarking, cognisant of the industry standards (IEC61400-2) is achieved by comparing the power predicting capability of both models $\left(\mathrm{P}_{\text {norm }}\right.$ and $\mathrm{P}_{\text {weib }}$ for the Albers and Weibull approximations respectively) against $\mathrm{P}_{\mathrm{abs}}$, which as the average of all powers produced (in terms of the Skystream characteristic) for each wind sample over the wind observation window (10 minutes). All three power measurements are contextualised with the industry standard method of measuring power, namely, by calculating the power based on the average wind speed over the 10 minute window $\left(\mathrm{P}_{\text {mean }}\right)$. Accuracy is determined on the basis of how well the models compare to $\mathrm{P}_{\mathrm{abs}}$.

The results confirm that both models are consistent with $\mathrm{P}_{\mathrm{abs}}$ and indeed, as illustrated in Figure 9 it is evident that over $90 \%$ of all simulated powers are within $50 \mathrm{~W}$ of the $\mathrm{P}_{\mathrm{abs}}$. The rating of the turbine is $2.5 \mathrm{~kW}$, so this would imply that $90 \%$ of readings are within $0.2 \%$ error. The Albers' approximation tends to over-predict (slightly) with the opposite outcome when using the Weibull approximation. Contrasted with the industry norm for evaluating power, it was observed that it significantly under-estimates at lower wind speeds and over estimates considerably at higher wind speeds (Figure 7). Both models are observed to introduce errors with increasing wind speed, but in comparison to the industry norm, these errors are negligible whereby significant errors are produced across the spectrum of practical wind speeds (Figure 10).In an energy context, the errors derived by the industry standard approach, results in an under-estimation of $24.2 \%$ and $20.5 \%$ at SUB1 and URB1 respectively (as detailed in Figure 8 and Table 2). The error associated with the Weibull approximation may be minimised further by reducing the dependency on random numbers and as such, is an area for future 
research. Another logical step for this research is to compare the models developed with output power observations from installed wind turbines of similar capacity to the power curve considered here.

However, there are issues with both models and in how they employ TI. TI does not facilitate chronological and time-indexed trending of the wind speed observations, where inter-variability of wind speed perpetuates turbulence. There is also a potential for unrealistic levels of TI within observations owing to gusting and occurrences of very low wind speeds. Such effects limit the practicality of the average TI as a metric, particularly if it is to be employed as a means to link a description of the urban environment $\left(\mathrm{z}_{0}\right)$ and average wind speed.

\section{Acknowledgements}

The authors would like to acknowledge the support of Dublin Institute of Technology and the Dublin Energy Lab. The wind velocity data is graciously provided by Dr. Rowan Fealy, of National University of Ireland, Maynooth (NUIM) and Dr. Gerald Mills, University College Dublin,(UCD) through the Dublin Urban Boundary Layer Experiment (DUBLex) collaboration. The authors would also like to acknowledge Axel Albers, for helpful comments at the early stages of the research. 


\section{REFERENCES}

[1] Heath M.A, Walshe J.D., and Watson S.J.. "Estimating the potential yield of small buildingmounted wind turbines," Wind Energy, vol. 10, pp. 271-287, 2007.

[2] Watson S., Infield D., and Harding M., "Predicting the Performance of Small Wind Turbines in the Roof-Top Urban Environment,", 2007.

[3] Ayhan D. and Sağlam Ş., "A technical review of building-mounted wind power systems and a sample simulation model," Renewable and Sustainable Energy Reviews, vol. 16, pp. 10401049, 2012.

[4] Encraft., "Warrick Wind Trials: Final Report," ed. UK, 2008.

[5] EST, "Location, Location, Location: Domestic small-scale wind field trial report," Energy Savings Trust2009.

[6] Islam M. R., Saidur R., and Rahim N. A., "Assessment of wind energy potentiality at Kudat and Labuan, Malaysia using Weibull distribution function," Energy, vol. 36, pp. 985-992, 2011.

[7] Cabello M. and Orza J. A. G., "Wind speed analysis in the province of Alicante, Spain. Potential for small-scale wind turbines," Renewable and Sustainable Energy Reviews, vol. 14, pp. 3185-3191, 2010.

[8] Fyrippis I., Axaopoulos P.J., and Panayiotou G., "Wind energy potential assessment in Naxos Island, Greece," Applied Energy, vol. 87, pp. 577-586, 2010.

[9] Kavak Akpinar E. and Akpinar S., "A statistical analysis of wind speed data used in installation of wind energy conversion systems," Energy Conversion and Management, vol. 46, pp. 515532, 2005.

[10] Jowder F. A. L., "Wind power analysis and site matching of wind turbine generators in Kingdom of Bahrain," Applied Energy, vol. 86, pp. 538-545, 2009.

[11] T. R. Oke, Boundary Layer Climates, 2nd ed.: Routledge, 1988.

[12] Wood C. R., Lacser A., Barlow J. F., Padhra A., Belcher S. E., Nemitz E., Helfter C., Famulari D., and Grimmond C. S. B., "Turbulent Flow at $190 \mathrm{~m}$ Height Above London During 2006-2008: A Climatology and the Applicability of Similarity Theory," Boundary-Layer Meteorology, vol. 137, pp. 77-96, 2010/10/01 2010.

[13] K. M. Sunderland, G. Mills, and M. F. Conlon, "Estimating the wind resource in an urban area: A case study of micro-wind generation potential in Dublin, Ireland," Journal of Wind Engineering and Industrial Aerodynamics, vol. 118, pp. 44-53, 2013.

[14] Metzger M., McKeoin B.J., and Holmes H., "The near neutral atmospheric surface layer: turbulence and non-stationarity," Philosophical Transactions of the Royal Society A: Mathematical, Physical and Engineering Sciences, vol. 365, pp. 859-876, 2007.

[15] Yersel M. and Gorble R., "Roughness effects on urban turbulence parameters," Boundary Layer Meteorology, vol. 37, pp. 271-284, 1986.

[16] Walker S. L., "Building mounted wind turbines and their suitability for the urban scale-A review of methods of estimating urban wind resource," Energy and Buildings, vol. 43, pp. 1852-1862, 2011.

[17] Fernando H. J. S., Zajic D. , Di Sabatino S., Dimitrova R., Hedquist B., and Dallman A., "Flow. turbulence and pollutant dispersion in urban atmospheres," PHYSICS OF FLUIDS, vol. 22, 2010.

[18] Fernando H. J. S., "Fluid mechanics of urban atmospheres in complex terrain," " Fluid Mech, vol. 42, p. 365, 2010.

[19] Sterwart I. and Oke T. R., "Newly Developed "Thermal Climate Zones" For Defining And Measureing Urban Heat Island Magnitude In The Canopy Layer," 2009.

[20] Landberg L., Myllerup L., Rathmann O., Petersen E. L., Jorgensen B. H., Badger J., and Mortensen N. G., "Wind Resource Estimation - An Overview," Wind Energy, vol. 6, pp. 261271, 2003.

[21] Pope S. B., Turbulent Flows: Cambridge University Press, 2000. 
[22] Burton T., Sharpe D., Jenkins N., and Bossanyi. E., Wind Energy Handbook: Wiley \& Sons Ltd., 2001.

[23] IEC, "International Standard 61400-2. Wind Turbines - Part 2: Design requirements for small turbines," ed, 2006.

[24] Rotach M.W., "Profiles of turbulence statistics in and above an urban street canyon," Atmospheric Environment, vol. 29, pp. 1473-1486, 1995.

[25] Mertens S., "Wind Energy in the Built Environment: Concentrator Effects of Buildings," Technische Universiteit Delft, PhD,2006.

[26] Rossen A. and Sheinman Y., "The average output power of a wind turbine in a turbulent wind," Wind Engineering \& Industrial Aerodynamics, vol. 51, pp. 287-302, 1994.

[27] Langreder W., Kaiser K., Hohlen H., and Hojstrup J., "Turbulence Correction for Power Curves," presented at the EWEC, London, 2004.

[28] Tindal A., Johnson C., LeBlanc M., Harman K., Rareshide E., Graves A-M., and America G. H., "Site-specific adjustments to wind turbine power curves," presented at the AWEA Wind Power Conference, Houston, 2008.

[29] Wagner R., Courtney S. M., Torben L. J., and Paulsen S. U., "Simulation of shear and turbulence impact on wind turbine power performance,", Riso DTU (National Laboratory for Sustainable Energy),2010.

[30] Cochran B., "The Influence of Atmospheric Turbulence on the Kinetic Energy Available During Small Wind Turbine Power Performance Testing,", IEA Expert Meeting on: Power Performance of Small Wind Turbines Not Connected to the Grid,2002.

[31] Lubitz W. D., "Impact of ambient turbulence on performance of a small wind turbine," Linkoping, Sweden, 2011.

[32] Carpman N., "Turbulence Intensity in Complex Environments and its Influence on Small Wind Turbines," Dept. of Earth Sciences, Uppsalla University, Uppsalla, 2010.

[33] Sheinman Y. and Rosen A., "A dynamic model of the influence of turbulence on the ppwer output of a wind turbine," Wind Engineering \& Industrial Aerodynamics, vol. 39, pp. 329-341, 1992.

[34] Albers A., "Turbulence Normalisation of Wind Turbine Power Curve Measurements," Deutsche WindGuard Consulting GmbH,2009.

[35] Campbell Scientific. (2011, CSAT3 , 3-D Sonic Anemometer. Available: http://www.campbellsci.com/csat3

[36] Hamad A. A. and Alsaad M., "Asoftware application for energy flow simulation of a grid connected ohotovoltaic systems," Energy Conversion and Management, vol. 51, pp. 1684-9, 2010.

[37] Archer C. L. and Jacobson M. Z. , "Spatial and temporal distributions of U.S. winds and wind power at 80 m derived from measurements," Journal of Geophysical Research, vol. 108, 2003.

[38] Justus C. G., HArgraves W. R., and Yalcin Ali, "Nationwide Assessment of Potential Output from Wind-Powered Generators," Applied Meteorolog, vol. 15, pp. 673-678.

[39] Seguro J. V. and Lambert T. W., "Modern estimation of the parameters of the Weibull wind speed distribution for wind energy analysis," Journal of Wind Engineering and Industrial Aerodynamics, vol. 85, pp. 75-84, 2000.

[40] Grimmond C.S.B and Oke T.R., "Aerodynamic properties of urban areas derived from analysis of surface form," Journal of Applied Meteorology, vol. 38, pp. 1262-1292, 1999. 